\title{
Characteristics and Treatment Outcome of Intracranial Aneurysms in Children and Adolescents
}

\author{
Sun Mo Nam, Donghwan Jang, ${ }^{1}$ Kyu-Chang Wang, ${ }^{2}$ Seung-Ki Kim, ${ }^{2}$ Ji Hoon Phi, ${ }^{2}$ Ji Yeoun Lee, ${ }^{2,3}$ Won-Sang Cho, \\ Jeong Eun Kim, ${ }^{1}$ Hyun-Seung Kang ${ }^{1}$ \\ Department of Neurosurgery,' Seoul National University Hospital, Seoul National University College of Medicine, Seoul, Korea \\ Division of Pediatric Neurosurgery, ${ }^{2}$ Seoul National University Children's Hospital, Seoul National University College of Medicine, Seoul, Korea \\ Department of Anatomy and Cell Biology, ${ }^{3}$ Seoul National University College of Medicine, Seoul, Korea
}

Objective : Intracranial aneurysms are not common in young age patients. We sought to find the characteristics of the intracranial aneurysms in patients under 20 years of age.

Methods : We reviewed 23 consecutive patients $\leq 20$ years of age treated for their intracranial aneurysms during the period from 1995 to 2017. From medical records and imaging studies, we gathered data on age, sex, presentation, associated medical condition, location and characteristics of aneurysms, treatment and clinical outcomes.

Results : The patients' ages ranged from 13 months to 20 years (median, 14 years). There were 16 males and seven females (male to female ratio, $2.3: 1$ ) with 31 aneurysms. Clinical presentations included sudden severe headache in $61 \%$, followed by altered mentality in $17 \%$ and seizure in $17 \%$. More than one-fourth patients had specific medical conditions related to the development of the cerebral aneurysms. The majority of aneurysms occurred in the anterior circulation (71\%), and were saccular (71\%). There were each three patients with false aneurysms (13\%) and giant aneurysms (13\%), and only one patient with multiple aneurysms (4\%). We treated 22 patients : 21 aneurysms with the endovascular methods, three with open surgery, and one with combined treatment. Good functional outcome could be achieved in $86 \%$ during the follow-up period.

Conclusion : In this series, the young-age patients with intracranial aneurysms were characterized by male predominance, related specific medical conditions, low incidence of multiple aneurysms, high incidence of giant aneurysms and good functional outcome after treatment.

Key Words : Aneurysm · Etiology · Pediatrics · Risk factors · Treatment outcome.

\section{INTRODUCTION}

The cerebral aneurysms in children are rare, and account for the frequency of $0.5 \%$ to $4.6 \%$ in large aneurysm series ${ }^{27}$.
Pediatric cerebral aneurysms have different characteristics from adult aneurysms in terms of demographic parameters, aneurysmal size, morphology, location, etiology, and outcome $^{1,3,6,11,12,15,16,19,22-24,27,30,31,35)}$. Nowadays, the detection rate of

\footnotetext{
- Received : June 13, 2019 •Revised : July 23, 2019 •Accepted : July 29, 2019

- Address for reprints : Hyun-Seung Kang

Department of Neurosurgery, Seoul National University Hospital, Seoul National University College of Medicine, 101 Daehak-ro, Jongno-gu, Seoul 03080, Korea Tel : +82-2-2072-1351, Fax : +82-2-744-8459, E-mail : kanghs@snuh.org, ORCID : https://orcid.org/0000-0002-6957-1907
}

This is an Open Access article distributed under the terms of the Creative Commons Attribution Non-Commercial License (http://creativecommons.org/licenses/by-nc/4.0) which permits unrestricted non-commercial use, distribution, and reproduction in any medium, provided the original work is properly cited. 
cerebral aneurysms has increased because of imaging technique development ${ }^{12)}$. In Korea, the incidence of intracranial aneurysms is 52.2/100000, and aneurysms in young age below 30 years account for $2 \%{ }^{20)}$. Reported case series are rare. This is the second study on the Korean pediatric cerebral aneurysms describing characteristics of patients and aneurysms, treatment outcome ${ }^{19)}$.

\section{MATERIALS AND METHODS}

This study was approved by the Institutional Review Board of Seoul National University's Hosptial (H-1905-125-1035). We searched patients $\leq 20$ years of an age who were diagnosed as 'aneurysm' between January 1995 and December 2017 from the department database in a tertiary care institution. We retrieved 28 patients. Among them, medical records were missing in two patients. One patient had aneurysm related with the arteriovenous malformation and another two patients had traumatic aneurysms on the superficial temporal artery. Finally, we included 23 patients in this study.

We reviewed the patients' medical records and radiologic data with a focus on the age at diagnosis, age at treatment, presenting symptoms, treatment modality, treatment outcome, and functional status at admission, at discharge and during the follow-up period. All the aneurysms were diagnosed with magnetic resonance (MR) or computed tomography (CT) angiography first and then with digital subtraction angiography. Hunt-Hess and modified Fisher grades were used for patients with ruptured aneurysms ${ }^{10,13,17)}$. The functional outcomes were assessed by modified Rankin scale (mRS) scores and were divided into three groups : good (mRS score, 0 to 2 ), significant residual morbidity (mRS score, 3 to 5), and death (mRS score, 6) $)^{4,29,34,36)}$.

\section{RESULTS}

There were 23 patients with 31 aneurysms including 16 males and seven females (male to female ratio, $2.3: 1$ ) (Table 1). The mean age at diagnosis was 14.4 years (range, 13 months to 20 years), and median age at diagnosis was 14 years (interquartile range, 7 years). Male to female ratio was $4: 1$ in the group of 10 years old or less, and became $2: 1$ in the group of
11 to 20 years old (Fig. 1). Clinical follow-up period ranged from 1 to 170 months (median, 42 months; mean, 55 months) and imaging follow-up period from 0 to 110 months (median, 37 months; mean, 42 months). The clinical follow-up data were available in all the patients, and the imaging follow-up data in 22 patients (96\%).

\section{Associated medical conditions}

Six patients had some specific medical conditions related to the intracranial aneurysms. The diagnoses included Kawasaki disease (case 1) ${ }^{2}$, ulcerative colitis (case 8), Sturge-Weber syndrome (case 10), type II microcephalic osteodysplastic primordial dwarfism (MOPD) (case 18), and moyamoya angiopathy (case 23). Moreover, a patient (case 12) has the family history of malignant hyperthermia and ryanodine receptor type 1 (RyR1) gene mutation (Fig. 2). One patient (case 3) had a developmental delay, but no specific diagnosis of genetic or congenital disorder was made for him. Three patients (cases 19,20 , and 22) had a clear history of head injury, and a 14-year-old boy (case 11) a history of cerebral infarction of undetermined cause. The other 13 patients had no specific medical history. In this series, there was no case of significant infection.

\section{Presentation}

There were 11 patients with ruptured aneurysms and 12 with unruptured aneurysms (Table 2). One patient (case 18) presented with subarachnoid hemorrhage three times resulting from the rupture of three different aneurysms. For the patients with the ruptured aneurysms, Hunt-Hess grade and modified Fisher grades on the initial CT are shown in Table 3. Four patients (36\%) showed intracerebral hemorrhage combined with subarachnoid hemorrhage. The most common presentation in these patients was sudden severe headache (5/11, 45\%), followed by altered mentality $(4 / 11,36 \%)$ and seizure (2/11, 18\%).

Among 12 patients with the unruptured aneurysms, two presented with seizures : one (case 2) of them had a large thrombosed middle cerebral artery aneurysm, and the other (case 10) had a posterior communicating artery aneurysm. The latter also had a visual field defect related to angiomatous changes in the brain. The other nine patients complained of headache as the initial presentation. Combined with headache, two of nine had vomiting and another two had dizziness. 
Pediatric Cerebral Aneurysms | Nam SM, et al.

Table 1. Demographic characteristics of the young-age aneurysm patients

\begin{tabular}{|c|c|c|c|c|c|c|c|}
\hline Case & $\begin{array}{c}\text { Age } \\
\text { (years) \& } \\
\text { sex }\end{array}$ & Size \& location & Characteristics & $\begin{array}{l}\text { Associated medical } \\
\text { condition }\end{array}$ & Treatment & $\begin{array}{l}\text { Follow } \\
\text { up } \\
\text { (months) }\end{array}$ & $\begin{array}{l}\text { Last mRS } \\
\text { score }\end{array}$ \\
\hline 1 & $1.1, \mathrm{M}$ & $\begin{array}{l}\text { Small, left MCA } \\
\text { bifurcation }\end{array}$ & $\begin{array}{l}\text { Ruptured, saccular, } \\
\text { thrombosed }\end{array}$ & Kawasaki disease & Surgical clipping & 62 & 1 \\
\hline 2 & $5, F$ & Large, right M2 & $\begin{array}{l}\text { Unruptured, saccular, } \\
\text { thrombosed }\end{array}$ & & Surgical clipping & 13 & 0 \\
\hline 3 & $8, M$ & Small, ACoA & Ruptured, saccular & $\begin{array}{l}\text { Cognitive dysfunction, } \\
\text { language } \\
\text { dysfunction }\end{array}$ & Coil embolization & 23 & 0 \\
\hline 4 & $9, M$ & $\begin{array}{l}\text { Small, right ICA } \\
\text { bifurcation }\end{array}$ & Ruptured, saccular & & Coil embolization $\rightarrow$ repeat embolization & 111 & 0 \\
\hline 5 & $10, M$ & Small, right P2 & $\begin{array}{l}\text { Unruptured, } \\
\text { dissecting, } \\
\text { thrombosed }\end{array}$ & & $\begin{array}{l}\text { Coil embolization } \rightarrow \text { endovascular } \\
\text { trapping }\end{array}$ & 76 & 0 \\
\hline 6 & $12, \mathrm{M}$ & Giant, left V4 & Unruptured, saccular & $\begin{array}{l}\text { History of pneumonia } \\
\text { at } 6 \text { months of age }\end{array}$ & Endovascular trapping & 26 & 1 \\
\hline 7 & $13, M$ & $\begin{array}{l}\text { Giant, right cavernous } \\
\text { ICA }\end{array}$ & Unruptured, saccular & & Endovascular trapping & 170 & 1 \\
\hline 8 & $13, F$ & $\begin{array}{l}\text { Small, right } \\
\text { supraclinoid ICA }\end{array}$ & Unruptured, saccular & Ulcerative colitis & Coil embolization & 42 & 0 \\
\hline 9 & $14, M$ & Small, left P2 & Ruptured, dissecting & $\begin{array}{l}\text { History of febrile } \\
\text { convulsion }\end{array}$ & $\begin{array}{l}\text { Stent-assisted coil embolization } \rightarrow \\
\text { endovascular trapping }\end{array}$ & 106 & 1 \\
\hline 10 & $14, \mathrm{~F}$ & Small, left PCoA & Unruptured, saccular & $\begin{array}{l}\text { Sturge-Weber } \\
\text { syndrome }\end{array}$ & Coil embolization & 50 & 1 \\
\hline 11 & $14, \mathrm{M}$ & Large, basilar top & Unruptured, fusiform & $\begin{array}{l}\text { History of cerebral } \\
\text { infarction, positive } \\
\text { antinuclear antibody }\end{array}$ & Observation & 1 & 1 \\
\hline 12 & $14, \mathrm{M}$ & Large, left PCoA & $\begin{array}{c}\text { Unruptured, } \\
\text { dissecting }\end{array}$ & $\begin{array}{l}\text { Family history } \\
\text { of malignant } \\
\text { hyperthermia }\end{array}$ & Stent-assisted coil embolization & 8 & 1 \\
\hline 13 & $15, M$ & Large, basilar trunk & Ruptured, dissecting & & Coil embolization & 1 & 6 \\
\hline 14 & $16, M$ & Small, right M1 & Unruptured, saccular & & Coil embolization & 31 & 1 \\
\hline 15 & $18, F$ & Small, left M1 & Ruptured, saccular & & Stent-assisted coil embolization & 111 & 0 \\
\hline 16 & $18, M$ & $\begin{array}{l}\text { Giant, right ICA } \\
\text { bifurcation }\end{array}$ & Unruptured, saccular & & $\begin{array}{l}\text { Bypass and endovascular trapping } \rightarrow \\
\text { surgical clipping }\end{array}$ & 104 & 1 \\
\hline 17 & $19, \mathrm{~F}$ & Small, left A1 & Unruptured, saccular & & Coil embolization & 119 & 0 \\
\hline 18 & $19, M$ & Small, left A2/3 & Ruptured, saccular & $\begin{array}{l}\text { Type II MOPD, small } \\
\text { for gestational age, } \\
\text { proteinuria }\end{array}$ & $\begin{array}{l}\text { Coil embolization } \rightarrow \text { coil embolization } \\
\text { for other unruptured and ruptured } \\
\text { aneurysms, surgical clipping for other } \\
\text { ruptured aneurysm }\end{array}$ & 33 & 1 \\
\hline 19 & $19, M$ & Small, left PICA & $\begin{array}{l}\text { Ruptured, dissecting; } \\
\text { traumatic }\end{array}$ & & Endovascular trapping & 20 & 1 \\
\hline 20 & $19, \mathrm{M}$ & Small, left PICA & $\begin{array}{l}\text { Ruptured, false } \\
\text { aneurysm; } \\
\text { traumatic }\end{array}$ & & Coil embolization & 62 & 4 \\
\hline 21 & $20, F$ & Large, right V4, large & $\begin{array}{l}\text { Unruptured, } \\
\text { dissecting, } \\
\text { thrombosed }\end{array}$ & & Endovascular trapping & 19 & 0 \\
\hline
\end{tabular}


Table 1. Continued

\begin{tabular}{|c|c|c|c|c|c|c|c|}
\hline Case & $\begin{array}{c}\text { Age } \\
\text { (years) \& } \\
\text { sex }\end{array}$ & Size \& location & Characteristics & $\begin{array}{l}\text { Associated medical } \\
\text { condition }\end{array}$ & Treatment & $\begin{array}{c}\text { Follow } \\
\text { up } \\
\text { (months) }\end{array}$ & $\begin{array}{l}\text { Last mRS } \\
\text { score }\end{array}$ \\
\hline 22 & $20, \mathrm{M}$ & Small, right distal ICA & $\begin{array}{l}\text { Ruptured, false } \\
\text { aneurysm; } \\
\text { traumatic }\end{array}$ & & Stent-assisted coil embolization & 15 & 3 \\
\hline 23 & $20, F$ & $\begin{array}{l}\text { Small, right medial } \\
\text { lenticulostriate artery }\end{array}$ & $\begin{array}{l}\text { Ruptured, false } \\
\text { aneurysm }\end{array}$ & $\begin{array}{l}\text { Moyamoya } \\
\text { angiopathy }\end{array}$ & Glue embolization & 68 & 2 \\
\hline
\end{tabular}

mRS : modified Rankin scale, M : male, MCA : middle cerebral artery, F : female, M2 : the second segment of the middle cerebral artery, ACoA : anterior communicating artery, ICA : internal carotid artery, P2 : the second segment of the posterior cerebral artery, V4 : the fourth segment of the vertebral artery, PCoA : posterior communicating artery, $\mathrm{M} 1$ : the first segment of the middle cerebral artery, A1 : the first segment of the anterior cerebral artery, $A 2 / 3$ : the junction of the second and the third segments of the anterior cerebral artery, MOPD : microcephalic osteodysplastic primordial dwarfism, PICA : posterior inferior cerebellar artery

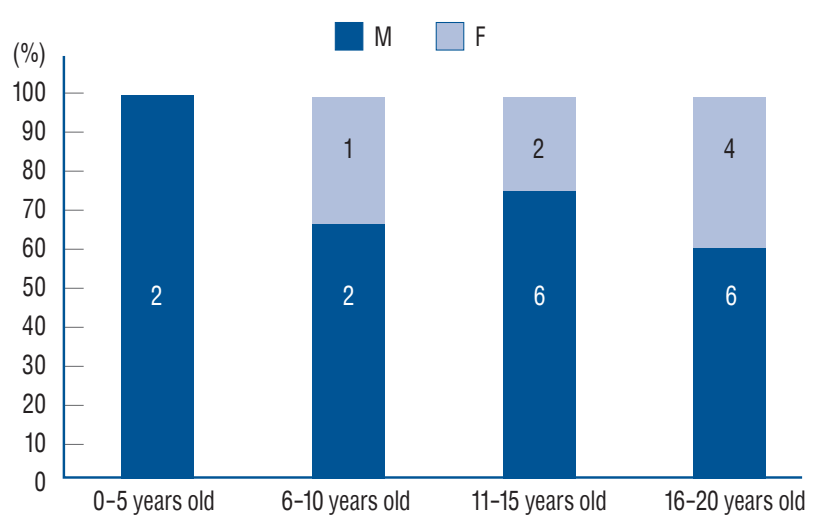

Fig. 1. Graph of sex distrubution according to the patents' ages. $M$ : male, $\mathrm{F}$ : female.

\section{Aneurysmal characteristics}

The characteristics of the aneurysms $(n=31)$ are presented in Table 4. In terms of size, there were nine aneurysms in sizes of $<3 \mathrm{~mm}$, four of 3-5 mm, six of 5-7 mm, three of 7-10 mm, six of 10-25 mm, and three of $>25 \mathrm{~mm}$. Thus, large and giant aneurysms accounted for 29\%. There were 22 anterior circulation and nine posterior circulation aneurysms (ratio, $2.4: 1$ ). There were nine aneurysms at the internal carotid artery, seven at the anterior cerebral artery, and six at the middle cerebral artery in the anterior circulation. In the posterior circulation, three at the posterior cerebral artery, two at the posterior inferior cerebellar artery, two at the distal vertebral artery, one at the basilar trunk, and one at the basilar top. Concerning the morphology, there were 21 saccular aneurysms (including three giant aneurysms), eight fusiform or dissecting aneurysms, and two traumatic false aneurysms. Only one patient (case 18) had multiple aneurysms, who was diagnosed as type
II MOPD and had nine aneurysms in total, including four in the anterior cerebral artery and two in the middle cerebral artery.

\section{Treatment}

Most of the patients $(n=19,83 \%)$ received endovascular treatment : endosaccular coil embolization in 16 aneurysms, endovascular trapping in four and glue embolization using nbutyl cyanoacrylate in one (see Table 1). Four patients (cases 9, 12,15 , and 22) underwent stent-assisted coil embolization for three ruptured and an unruptured aneurysms. Combined endovascular and surgical treatment was performed in one patient (case 16) (Fig. 3). Two patients (cases 1 and 2) underwent surgical clipping for a ruptured and an unruptured middle cerebral artery aneurysms. Our patient with multiple aneurysms (case 18) underwent coil embolization for two ruptured and three unruptured aneurysms and surgical clipping for one ruptured aneurysm. One patient (case 11) with fusiform aneurysm at the basilar top was recommended observation, but was lost to follow up.

Four patients underwent additional treatments due to incomplete results of the previous treatment (see Table 1). A 14-year-old boy (case 9) underwent stent-assisted coil embolization due to a ruptured dissecting aneurysm at the P2 segment of the posterior cerebral artery ${ }^{25)}$. Because of re-bleeding, endovascular trapping was done. The second patient (case 4) was a 9-year-old boy presenting with a ruptured aneurysm at the bifurcation of the internal carotid artery. During the follow-up period, he needed two additional sessions of coil embolization after 22 and 40 months later for the recurrent aneu- 

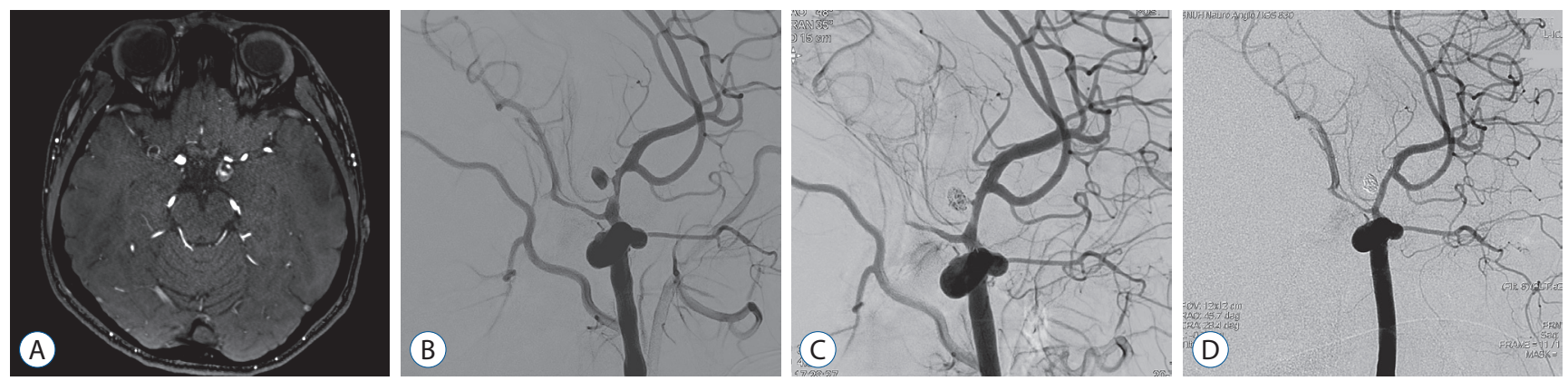

Fig. 2. A 14-year-old boy (case 12) presented with aggravating headache and nausea. His headache began 5 years ago on the left temple area, with no neurological deficit. He had no other past medical history. His mother and maternal grandfather had history of malignant hyperthermia and ryanodine receptor type 1 (RyR1) gene mutation. A : Magnetic resonance imaging showed a thrombosed aneurysm on the distal internal carotid artery (C1 segment). B : Cerebral angiography demonstrated an aneurysm of $9.8 \mathrm{~mm}$ in diameter at the stenosed communicating segment of the left internal carotid artery. C: He underwent endosaccular coil embolization with stent assistance. D : Follow-up cerebral angiography at 10 months after treatment showed no evidence of recurrence.

Table 2. Clinical presentation of the pediatric aneurysm patients

\begin{tabular}{lcc} 
& Ruptured & Unruptured \\
\hline Severe headache & $5(45)$ & $9(75)$ \\
Seizure & $2(18)$ & $2(17)$ \\
Altered mentality & $4(36)$ & 0 \\
Cranial nerve palsy & 0 & $1(8)$ \\
\hline
\end{tabular}

Values are presented as number (\%)

Table 3. Hunt-Hess grade and modified Fisher grade in the pediatric aneurysm patients

\begin{tabular}{lc}
\hline Grade & Value \\
\hline Hunt-Hess grade & \\
I & $2(18)$ \\
II & $3(27)$ \\
III & $3(27)$ \\
IV & $3(27)$ \\
V & 0 \\
Modified Fisher grade & \\
I & 0 \\
II & $2(18)$ \\
III & $5(45)$ \\
IV & $4(36)$ \\
\hline
\end{tabular}

Values are presented as number (\%)

rysm. The third patient (case 5) underwent the endovascular trapping for recurrent thrombosed posterior cerebral artery aneurysm at the P2 segment. The fourth patient (case 16) was an 18-year-old boy with an unruptured giant aneurysm (35.4 $\mathrm{mm}$ in the maximal diameter) at the internal carotid artery
Table 4. Location and morphology of the aneurysms in the pediatric aneurysm patients

\begin{tabular}{lcc}
\hline & Ruptured & Unruptured \\
\hline Location & $3(21)$ & $6(35)$ \\
Internal cerebral artery & $3(21)$ & $3(18)$ \\
Middle cerebral artery & $4(29)$ & $3(18)$ \\
Anterior cerebral artery & $4(29)$ & $5(29)$ \\
Posterior circulation & & \\
Morphology & $8(57)$ & $13(76)$ \\
Saccular & $3(21)$ & $4(24)$ \\
Dissecting/Fusiform & $3(21)$ & 0 \\
False &
\end{tabular}

Values are presented as number (\%)

bifurcation treated by surgical bypass using the saphenous vein and endovascular trapping. However, the aneurysm ruptured 2 weeks later, and he underwent additional surgical and endovascular trapping. The bypass remained patent for 85 months.

\section{Outcome}

The mRS scores of patients who underwent treatment were obtained at the time of admission, at discharge and at the last outpatient check-up. Most patients ( $\mathrm{n}=18,82 \%)$ were functionally good at the time of final assessment (see Table 1). The clinical outcome is presented according to the age group in Table 5. The proportion of patients with significant morbidity (mRS scores, 3 to 5) reduced from 32\% (7 of 22) at discharge to $9 \%$ (2 of 22) at the last follow-up. The mean follow-up in- 

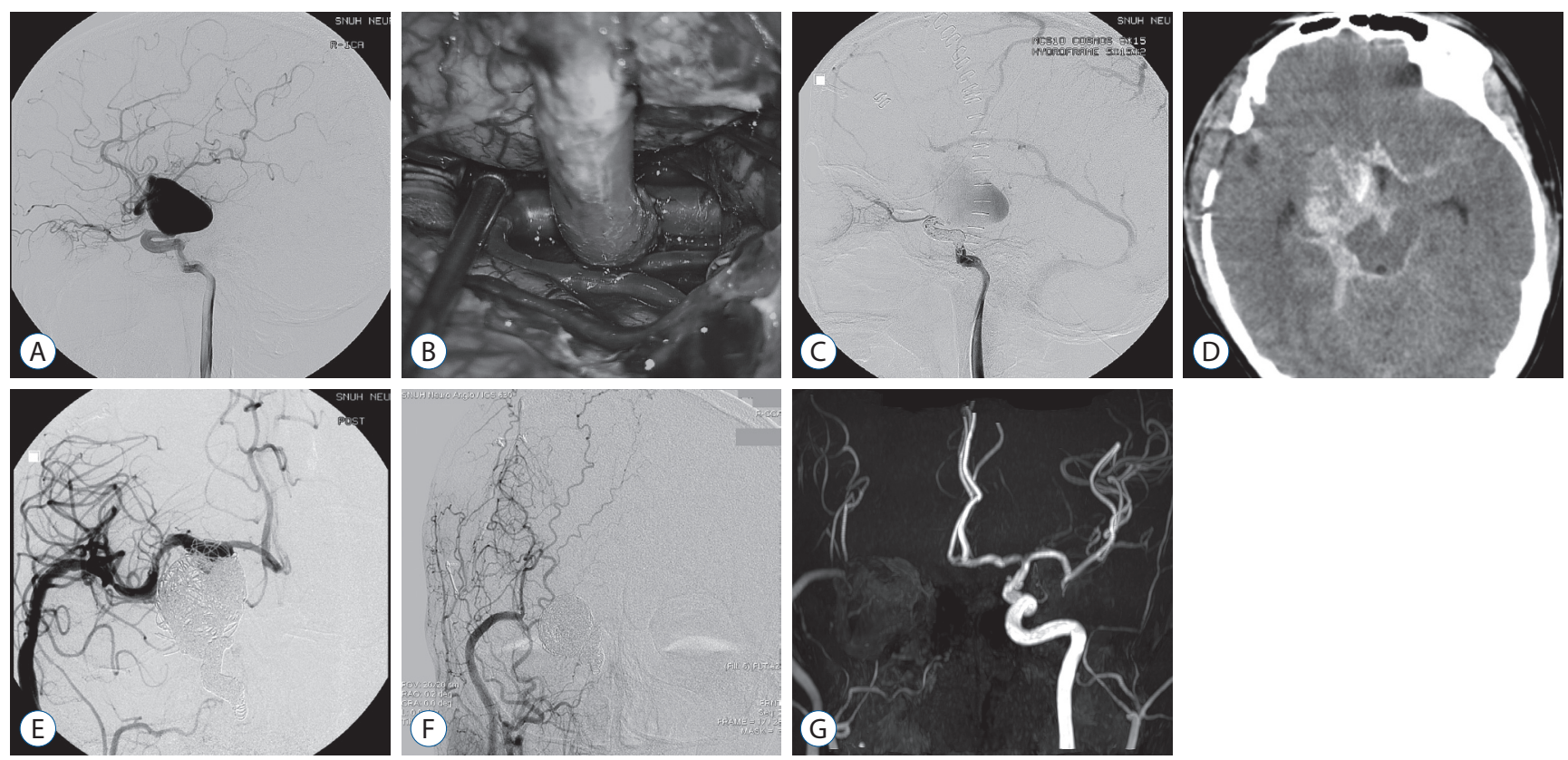

Fig. 3. A 18-year-old boy (case 16) presented with headache. A : Cerebral angiography showed a giant aneurysm of $35.4 \mathrm{~mm}$ in maximal diameter at internal cerebral artery bifurcation. $\mathrm{B}$ : An intra-operative photograph of external carotid artery to middle cerebral artery bypass using the saphenous vein. $C$ : Endovascular trapping of internal cerebral artery was performed. D: Two weaks later, rebleeding was found. E: Additional endovascular trapping was performed. In addition, surgical clipping and intracerebral hematoma evacuation were performed (not shown). F and G : Five-year follow-up cerebral angiography (F) and 7-year followup magnetic resonance angiography $(\mathrm{G})$ showed patent bypass flow.

Table 5. Clinical outcome as mRS score of the young-age aneurysm patients according to ages

\begin{tabular}{lccc}
\hline Age (years) & mRS 0-2 & mRS 3-5 & mRS 6 \\
\hline 0 to 5 & 2 & & \\
6 to 10 & 3 & & 1 \\
11 to 15 & 7 & 2 & \\
16 to 20 & 7 & & \\
\hline
\end{tabular}

mRS : modified Rankin scale

terval was 49 months (range, 1 to 170 months). The average mRS score was 2.0 at the time of admission, 1.9 at discharge and 1.1 at the outpatient check-up. The clinical outcome tended to be better in patients with unruptured aneurysms $(p=0.090)$ (Fig. 4), and in younger patients (under 15 years of age) $(p=0.037)$.

There was one mortality in this series. A 15 -year-old boy (case 13) presented with diagnosis of subarachnoid hemorrhage due to a ruptured dissecting aneurysm on basilar artery in November 1995. He suffered from rebleeding and further rebleeding 6 days and 7 days after admission. He underwent endosaccular coil embolization 11 days after admission, but eventually he died 1 month later. There were three morbidity cases. A 12-year-old boy (case 6) with a giant unruptured aneurysm at the distal vertebral artery suffered rupture before appropriate treatment. He discharged with the mRS score of 3. The other two morbidities (case 9 and 16) were related to posttreatment rebleeding as described previously.

The long-term durability of endovascular treatment was good in the majority of patients. Four (cases 4, 5, 9, and 16) of 20 patients required retreatment. The three patients (cases 12, 15, and 22), except for case 9, undergoing stent-assisted coiling demonstrated stable outcome during the follow-up period of average 21 months.

\section{DISCUSSION}

\section{Aneurysm as the cause of stroke in young-age pa- tients}

In our series of young-age cerebral aneurysms, severe headache was the most common symptom. Seizure accounted for $17 \%$. Seizure is known to be twice frequent in pediatric aneurysm patients than in adults ${ }^{1,6,11,16,23)}$. In children, clinicians should be cautious in its evaluation ${ }^{11,15,26)}$. In our series, cranial 


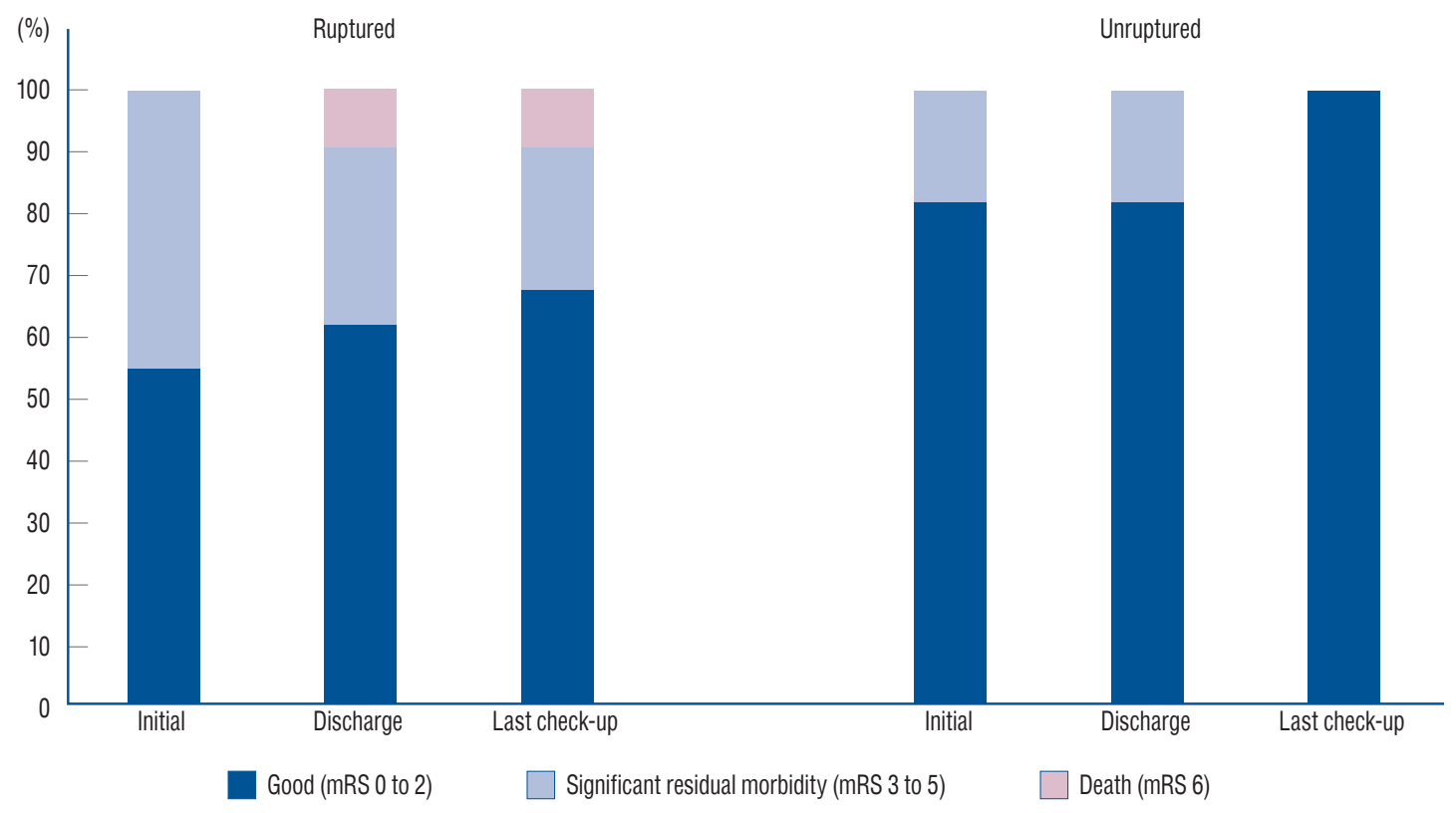

Fig. 4. A graph of functional outcome according to rupture status of aneurysms at the times of admission and discharge and at the last outpatient check-up. mRS : modified Rankin scale.

nerve palsy (4\%) was less frequent than in other series of pediatric aneurysms $(15 \% \text { to } 50 \%)^{12,16,23)}$. It might be caused by the lower rate of large and giant aneurysms in our series (29\%) than other series $(40 \%)^{19)}$.

In general, intracranial aneurysm is more prevalent among females $(1.56: 1)$ in Korea ${ }^{20)}$. However, male predominance was observed in this series of young-age aneurysms, and the male to female ratio was $2.3: 1$. This was consistent with the previous studies of pediatric aneurysms ${ }^{11,12,16,23,24,31}$. Male predominance became less conspicuous in the old children group $^{1)}$. In this series, male to female ratio was $4: 1$ in the group of 10 years old or less, and became $2: 1$ in the group of 11 to 20 years old.

\section{Associated medical conditions in young-age an- eurysm patients}

Smoking, hypertension, excessive alcohol consumption and family history are known risk factors of intracranial aneurysms in general ${ }^{7,20)}$. Children usually do not have such risk factors. In a study, the incidences of cardiovascular diseases, hypercholesterolemia and hypertension were not higher in the pediatric aneurysm patients than in the normal population ${ }^{22}$. Other mechanisms seem to generate an aneurysm in youngage patients, such as genetic influence or other medical comorbidities. Similar to our series, there was a report more than one fourth (28\%) pediatric aneurysm patients had medical comorbidities ${ }^{30)}$.

In this series of young-age aneurysms, six patients (26\%) had specific medical conditions, which included Sturge-Weber syndrome, type II MOPD, Kawasaki disease, moyamoya disease, ulcerative colitis, and the family history of RyR1 gene mutation. Sturge-Weber syndrome shows the feature of abnormal capillary venous vessels in the leptomeninges of the brain and choroid ${ }^{32)}$. There is a case report of 32-year-old patient with Sturge-Weber syndrome and subarachnoid hemorrhage and two case reports of Sturge-weber syndrome associated with intracerebral hemorrhage (one of them also had autosomal dominant polycystic kidney disease ${ }^{8,28}$. In our series, the 14-year-old girl (case 10) with Sturge-Weber syndrome and the posterior communicating artery aneurysm also had hypertension, renal artery stenosis and femoral artery stenosis.

Type II MOPD is a well-established cause of cerebral aneurysms. It causes disorganized mitotic spindles and mis-segregation of chromosomes, and develops cerebrovascular diseases such as moyamoya disease and cerebral aneurysms $\mathrm{s}^{5}$. Our patient with type II MOPD (case 18) had nine aneurysms and underwent coil embolization for four and surgical clipping for one. Kawasaki disease makes inflammation on the walls of small- and medium-sized arteries throughout the body, and is 
related to the coronary arterial aneurysm ${ }^{14,21)}$. There have been three case reports of cerebral aneurysms in association with Kawasaki disease, including ours ${ }^{2,14,33)}$. The pathologic specimen revealed invasion of inflammatory cells supporting Kawasaki disease as the cause of the cerebral aneurysm.

Inflammatory bowel disease has a non-coincidental association with vasculitides, such as Takayasu vasculitis, large-vessel vasculitis, antineutrophil cytoplasmic antibody-associated vasculitis, and cutaneous vasculitis. Further research is needed on the association with intracranial aneurysms. RyR1 gene mutation is the cause of malignant hyperthermia, and is very rare as its prevalence is $1 / 90000$. It is related to the muscular calcium channel, which has a crucial role in vasoconstriction and hemostasis ${ }^{9,37)}$. Family history of malignant hyperthermia and RyR1 gene mutation may be a risk factor of the intracranial aneurysm. There is a study suggesting the relation with aneurysmal subarachnoid hemorrhage ${ }^{9)}$.

Aside from the specific disease conditions, trauma is one of the most important causes of the young age aneurysms ${ }^{12)}$. Traumatic aneurysms accounted for $13 \%$ in this series, which is comparable to the proportions in the literature $(14 \%$ to $39 \%)^{12)}$.

\section{Aneurysm characteristics in young-age patients}

In the pediatric group, there are a higher proportion of aneurysms in the posterior circulation, a higher frequency of giant aneurysms than in adults, and a predilection for the internal carotid artery bifurcation ${ }^{1,31)}$. In this study, the distal internal carotid artery was the most common site (26\%). In this series, $13 \%$ of the patients presented as having giant aneurysms, which corresponded to rather a lower proportion compared to those reported in the literature (14\% to 51\%) but was still higher compared to the adult series ${ }^{1,11,12,23,27,31)}$. There was no infectious aneurysm in our study, different from those in the literature (7\% to $15 \%)^{1,12,16,23,24)}$.

\section{Treatment and outcome in young-age aneurysm patients}

In this series, the majority (83\%) of the patients were treated by endovascular means. Among the patients treated with endovascular means in our center, 14\% needed additional treatment during the follow-up period. Overall, $82 \%$ of those treated demonstrated good functional outcome measured despite half of the patients presented with ruptured aneurysms.
Patients with unruptured aneurysms and younger patients under 15 years of age showed better outcome. Endovascular treatment showed good functional outcome and obliteration rate similar to surgical treatment ${ }^{1,12,23,24,31}$. Recurrence is a concern because of a long life expectancy and problems related to growth. In a study, the recurrence rate of the endovascular treatment was $14 \%$ (mean follow-up period of 5.7 years $)^{30)}$. In regard to the stent-assisted treatment, our data showed a good patency of the stented segment and stable aneurysmal occlusion without complication during the follow-up period of average 21 months. A study showed safety of stenting in children except for a procedure-related mortality ${ }^{35)}$. The patency of stents was maintained in $80 \%$ of patients for 8 to 36 months. Thus, we suggest usage of stent could be the option for complex aneurysm such as giant or dissecting in pediatric patients. In our series, the youngest age of patients undergoing coil embolization and stent-assisted coil embolization was 8 years and 14 years, respectively.

Pediatric aneurysm surgery has shown good obliteration rates of $68 \%$ to $94 \%{ }^{16,18,22,30)}$. In our series, three patients underwent surgical clipping (cases 1,2, and 18), and a patient bypass surgery (case 16), with good clinical outcomes. The bypass patency seems to be maintained well although there can be concerns related to the physical growth of children ${ }^{18)}$. Compared to adult population, pediatric patients have shown good functional status after treatment ${ }^{6,11,12,16,19,23,24,27,30,31,35)}$.

\section{CONCLUSION}

As a rare disease in pediatric population, intracranial aneurysm is an on-going studying subject. More than one fourth of patients in our series have the specific medical conditions related to the aneurysm, thus making it important to review carefully the previous medical history in young-age aneurysm patients. The endovascular treatment as the predominant means produced good clinical outcome. In this series, the young-age patients with intracranial aneurysms were characterized by male predominance, low incidence of multiple aneurysms, high incidence of giant aneurysms and good functional outcome after treatment. 


\section{CONFLICTS OF INTEREST}

No potential conflict of interest relevant to this article was reported.

\section{INFORMED CONSENT}

This type of study does not require informed consent.

\section{AUTHOR CONTRIBUTIONS}

\author{
Conceptualization : HSK \\ Data curation : SMN \\ Formal analysis : SMN \\ Funding acquisition : HSK \\ Methodology: HSK \\ Project administration : DJ \\ Visualization : SMN \\ Writing - original draft : SMN \\ Writing - review \& editing : HSK, KCW, DJ, KCW, SKK, \\ JHP, JYL, WSC, JEK
}

\section{References}

1. Agid R, Souza MP, Reintamm G, Armstrong D, Dirks P, TerBrugge KG : The role of endovascular treatment for pediatric aneurysms. Childs Nerv Syst $21:$ 1030-1036, 2005

2. Ahn JH, Phi JH, Kang HS, Wang KC, Cho BK, Lee JY, et al. : A ruptured middle cerebral artery aneurysm in a 13-month-old boy with Kawasaki disease. J Neurosurg Pediatr 6 : 150-153, 2010

3. Beslow LA, Jordan LC : Pediatric stroke: the importance of cerebral arteriopathy and vascular malformations. Childs Nerv Syst 26 : 12631273,2010

4. Bigi S, Fischer U, Wehrli E, Mattle HP, Boltshauser E, Bürki S, et al. : Acute ischemic stroke in children versus young adults. Ann Neurol 70 : 245-254, 2011

5. Bober MB, Jackson AP : Microcephalic osteodysplastic primordial dwarfism, type II: a clinical review. Curr Osteoporos Rep 15 : 61-69, 2017

6. Chen R, Zhang S, Guo R, Ma L, You C : Pediatric intracranial distal arterial aneurysms: report of 35 cases. Acta Neurochir (Wien) 160 : 1633-1642, 2018

7. Cho WS, Kim JE, Park SQ, Ko JK, Kim DW, Park JC, et al. : Korean clinical practice guidelines for aneurysmal subarachnoid hemorrhage. J Korean Neurosurg Soc 61 : 127-166, 2018
8. Chonan M, Suzuki Y, Haryu S, Mashiyama S, Tominaga T : Sturge-Weber syndrome with intracerebral hemorrhage: a case report. Springerplus $5:$ : 1746, 2016

9. Coburger J, Kapapa T, Wirtz CR, Jurkat-Rott K, Klingler W : High prevalence of rare ryanodine receptor type 1 variants in patients suffering from aneurysmatic subarachnoid hemorrhage: a pilot study. J Clin Neurosci 45 : 209-213, 2017

10. Frontera JA, Claassen J, Schmidt JM, Wartenberg KE, Temes R, Connolly ES Jr, et al. : Predicion of symptomatic vasospasm aftter subarachnoid hemorrhage: the modified Fisher scale. Neurosurgery 59 : 21-27; discussion 21-27, 2006

11. Hetts SW, Narvid J, Sanai N, Lawton MT, Gupta N, Fullerton HJ, et al. : Intracranial aneurysms in childhood: 27-year single-institution experience. AJNR Am J Neuroradiol 30 : 1315-1324, 2009

12. Huang J, McGirt MJ, Gailloud P, Tamargo RJ : Intracranial aneurysms in the pediatric population: case series and literature review. Surg Neurol 63 : 424-432; discussion 432-433, 2005

13. Hunt WE, Hess RM : Surgical risk as related to time of intervention in the repair of intracranial aneurysms. J Neurosurg $28:$ 14-20, 1968

14. Ishida A, Matsuo S, Kawamura S, Nishikawa T : Subarachnoid hemorrhage due to nonbranching aneurysm of the middle cerebral artery in a young adult with a history of Kawasaki disease. Surg Neurol Int $5: 5$, 2014

15. Jeong G, Lim BC, Chae JH : Pediatric stroke. J Korean Neurosurg Soc 57 : 396-400, 2015

16. Kakarla UK, Beres EJ, Ponce FA, Chang SW, Deshmukh VR, Bambakidis $N C$, et al. : Microsurgical treatment of pediatric intracranial aneurysms: long-term angiographic and clinical outcomes. Neurosurgery 67 : 237-249; discussion 250, 2010

17. Kapapa $T$, Tjahjadi M, König R, Wirtz CR, Woischneck $D$ : Which clinical variable influences health-related quality of life the most after spontaneous subarachnoid hemorrhage? Hunt and Hess scale, Fisher score, world federation of neurosurgeons score, brussels coma score, and glasgow coma score compared. World Neurosurg $80: 853-858,2013$

18. Kim LJ, Tariq F, Sekhar LN : Pediatric bypasses for aneurysms and skull base tumors: short- and long-term outcomes. J Neurosurg Pediatr 11 : 533-542, 2013

19. Kim M, Lee HS, Lee S, Park JC, Ahn JS, Kwon DH, et al. : Pediatric intracranial aneurysms: favorable outcomes despite rareness and complexity. World Neurosurg 125 : e1203-e1206, 2019

20. Kim T, Lee H, Ahn S, Kwon OK, Bang JS, Hwang G, et al. : Incidence and risk factors of intracranial aneurysm: a national cohort study in Korea. Int J Stroke 11 : 917-927, 2016

21. Koren $G$, Lavi $S$, Rose $V$, Rowe $R$ : Kawasaki disease: review of risk factors for coronary aneurysms. J Pediatr 108 : 388-392, 1986

22. Koroknay-Pál P, Laakso A, Lehto H, Seppä K, Kivisaari R, Hernesniemi $J$, et al. : Long-term excess mortality in pediatric patients with cerebral aneurysms. Stroke 43 : 2091-2096, 2012

23. Krishna H, Wani AA, Behari S, Banerji D, Chhabra DK, Jain VK : Intracranial aneurysms in patients 18 years of age or under, are they different from aneurysms in adult population? Acta Neurochir (Wien) 147 : 
469-476; discussion 476, 2005

24. Lasjaunias P, Wuppalapati S, Alvarez H, Rodesch G, Ozanne A : Intracranial aneurysms in children aged under 15 years: review of 59 consecutive children with 75 aneurysms. Childs Nerv Syst $21:$ 437-450, 2005

25. Lee JY, Kwon BJ, Kang HS, Wang KC : Subarachnoid hemorrhage from a dissecting aneurysm of the posterior cerebral artery in a child: rebleeding after stent-assisted coiling followed by stent-within-stent technique. J Korean Neurosurg Soc 49 : 134-138, 2011

26. Lo WD : Childhood hemorrhagic stroke: an important but understudied problem. J Child Neurol 26 : 1174-1185, 2011

27. Meyer FB, Sundt TM Jr, Fode NC, Morgan MK, Forbes GS, Mellinger JF : Cerebral aneurysms in childhood and adolescence. J Neurosurg 70 : 420-425, 1989

28. Niemczyk M, Niemczyk R, Gradzik M, Niemczyk S, Kecik D, Paczek L : Sturge-Weber syndrome coexisting with autosomal dominant polycystic kidney disease. Int Urol Nephrol 45 : 923-924, 2013

29. Rankin $\mathrm{J}$ : Cerebral vascular accidents in patients over the age of 60 . II. Prognosis. Scott Med J 2 : 200-215, 1957

30. Sanai N, Quinones-Hinojosa A, Gupta NM, Perry V, Sun PP, Wilson CB, et al. : Pediatric intracranial aneurysms: durability of treatment following microsurgical and endovascular management. J Neurosurg 104(2
Suppl) : 82-89, 2006

31. Saraf $R$, Shrivastava $M$, Siddhartha $W$, Limaye $U$ : Intracranial pediatric aneurysms: endovascular treatment and its outcome. J Neurosurg Pediatr $10: 230-240,2012$

32. Shirley MD, Tang H, Gallione CJ, Baugher JD, Frelin LP, Cohen B, et al. : Sturge-Weber syndrome and port-wine stains caused by somatic mutation in GNAQ. N Engl J Med 368 : 1971-1979, 2013

33. Tanaka S, Sagiuchi T, Kobayashi I : Ruptured pediatric posterior cerebral artery aneurysm 9 years after the onset of Kawasaki disease: a case report. Childs Nerv Syst 23 : 701-706, 2007

34. van Swieten JC, Koudstaal PJ, Visser MC, Schouten HJ, van Gijn J : Interobserver agreement for the assessment of handicap in stroke patients. Stroke $19: 604-607,1988$

35. Vargas SA, Diaz C, Herrera DA, Dublin AB : Intracranial aneurysms in children: the role of stenting and flow-diversion. J Neuroimaging 26 : 41-45, 2016

36. Weisscher N, Vermeulen M, Roos YB, de Haan RJ : What should be defined as good outcome in stroke trials; a modified Rankin score of $0-1$ or $0-2$ ? J Neurol $255: 867-874,2008$

37. Witherspoon JW, Meilleur KG : Review of RyR1 pathway and associated pathomechanisms. Acta Neuropathol Commun 4 : 121, 2016 